\title{
Guanidine derived ionic liquids: catalyst free medium for N-Formylation of amines
}

\author{
Jafar Akbari, ${ }^{* a}$ Malak Hekmati, ${ }^{a}$ Mehdi Sheykhan, ${ }^{b}$ and Akbar Heydari ${ }^{\text {b }}$ \\ ${ }^{a}$ Chemistry Department, Islamic Azad University, Buinzahra Branch, Buinzahra, Iran \\ ${ }^{b}$ Chemistry Department, Tarbiat Modares University, Tehran. Iran \\ E-mail:__akbari@modares.ac.ir
}

\begin{abstract}
A remarkable improvement of both the chemical yield and the reaction condition, of $N$ formylation of amines with formic acid was found, when tetra-substituted guanidinium salts were added as ionic liquids. Effects of amount and the type of guanidinium salts on the outcome of the reaction were investigated. This procedure works well for sterically hindered primary amine as well as electron-deficient primary arylamines, primary and secondary amino alcohols, $\alpha$-amino acid esters, hydroxylamines and $N, N$-dimethylhydrazine. The recovered ionic liquid can be recycled for four runs without loss of activity
\end{abstract}

Keywords: Guanidine based ionic liquid, formylation, protic ionic liquid, chemoselective, recycling

\section{Introduction}

One of the most useful and versatile functional groups to be introduced into an organic molecule is the formyl group. Formamides have been widely used in organic synthesis as protecting group of amines, ${ }^{1}$ precursor for isocyanide preparation, ${ }^{2,3}$ an intermediate for mono methylated of primary amines. ${ }^{4}$ In addition, they have been used in the synthesis of formamidines. ${ }^{5}$ Thus a number of formylating methods have been reported. Acetic formic anhydride ${ }^{6}$ continues to be the most widely used formylating reagent, but it is sensitive to atmospheric moisture and cannot be stored due to decomposition to acetic acid and carbon monoxide. Many other useful formylation reagents have been reported such as chloral, ${ }^{7}$ activated formic acid using DCC $^{8}$ or EDCI, ${ }^{9}$ activated formic esters, ${ }^{10}$ ammonium formate, ${ }^{11}$ 2,2,2-trifluoroethyl formate ${ }^{12}$ and $a q .85 \%$ formic acid and $\mathrm{ZnO}^{13}$ Recently polyethylene glycol has been reported as a medium for formylation of aniline derivatives with formic acid. ${ }^{14}$ However, many of these methods suffer from different drawbacks such as long reaction times, high temperature, the application of 
expensive and toxic formylating agents and catalysts. Thus, there is still scope to develop a simple and practical method for the $\mathrm{N}$-formylation of amines under mild conditions.

In recent years, ionic liquids have emerged as a useful alternative to conventional organic solvents or catalysts due to their particular properties, such as negligible vapor pressure, chemical stability, excellent solvent power for organic and inorganic compounds, as well as the ease of recovery. ${ }^{15}$ Recently, much attention has been focused on organic reactions promoted by ionic liquids. Protic ionic liquids are one of the successful examples as reaction medium and catalysts in organic synthesis. ${ }^{16-20}$ Protic ionic liquids, especially those based on the $1,1,3,3$ tetramethylguanidine (TMG) and synthesized through simple neutralizing of equimolar TMG with acids ${ }^{21}$ have been found to be useful in preparing an immobilized catalyst for hydrogenation of olefins, ${ }^{22}$ absorbing $\mathrm{SO}_{2}$ from simulated flue gases, ${ }^{23}$ homogeneous and recoverable acidic catalysts for Henry reaction, ${ }^{24}$ one-pot synthesis of pyran ${ }^{25}$, synthesis of 3,4-dihydropyridin-2$(1 H)$-ones $^{26}$ and direct aldol reaction ${ }^{27}$. To the best of our knowledge, there is no example on the use of ionic liquids as promoter for the $\mathrm{N}$-formylation of amines.

\section{Results and Discussion}

In the initial experiments, in order to examine the optimum conditions and catalytic activity of different ionic liquids: [TMG][Ac], [TMG][TFA], $[\mathrm{TMG}]\left[\mathrm{NO}_{3}\right]$ and $[\mathrm{TMG}][\mathrm{OTf}]$ in $\mathrm{N}$-formylation of amines, reaction of aniline, benzylamine and dibenzylamine was selected as model (Scheme 1).

\begin{tabular}{|c|c|c|c|c|c|}
\hline entry & Substrate & Product & Ionic liquid & time (min) & Yield $3 \%$ \\
\hline \multirow{4}{*}{$\mathrm{a}$} & $\mathrm{H}$ & $\mathrm{H}_{1}$ & {$[\mathrm{TMG}][\mathrm{Ac}]$} & 5 & 96 \\
\hline & & & {$[\mathrm{TMG}][\mathrm{TFA}]$} & 5 & 98 \\
\hline & & & {$[\mathrm{TMG}]\left[\mathrm{NO}_{3}\right]$} & 10 & 96 \\
\hline & & & [TMG][OTf] & 10 & 96 \\
\hline \multirow{4}{*}{ b } & & & {$[\mathrm{TMG}][\mathrm{Ac}]$} & $12 \mathrm{~h}$ & 65 \\
\hline & & & {$[\mathrm{TMG}][\mathrm{TFA}$} & 5 & 98 \\
\hline & & & {$[\mathrm{TMG}]\left[\mathrm{NO}_{3}\right]$} & $12 \mathrm{~h}$ & 45 \\
\hline & & & [TMG][OTf] & 24 & 55 \\
\hline & $\widehat{\curvearrowright}_{\mathrm{Ph}}$ & $N^{\prime}$ & {$[\mathrm{TMG}][\mathrm{Ac}]$} & $15 \mathrm{~h}$ & 55 \\
\hline & $\mathrm{H}$ & $\stackrel{1}{\mathrm{C}} \mathrm{HO}$ & {$[\mathrm{TMG}][\mathrm{TFA}]$} & 15 & 96 \\
\hline & & & {$[\mathrm{TMG}]\left[\mathrm{NO}_{3}\right]$} & $24 \mathrm{~h}$ & 60 \\
\hline & & & [TMG][OTf] & 15 & 45 \\
\hline
\end{tabular}

Scheme 1. Formylation of amines $(1 \mathrm{mmol})$ with aq. $85 \%$ formic acid $(1.2 \mathrm{mmol})$ in the presence of different TMG ionic liquid (1 mmol). 
The results indicate that $[\mathrm{TMG}][\mathrm{TFA}]$ has the highest activity for $\mathrm{N}$-formylation reactions among the four ionic liquid catalyzed reactions. In view of these results and due to the fact that, to our knowledge, the use of formic acid as formylating agent together with [TMG][TFA] was never reported in the literature, our studies were directed into examination of scope of reaction for $\mathrm{N}$-formylation of various amines and amine derivatives. Aniline undergoes quantitative formylation at a much faster rate $(5 \mathrm{~min}$ ) in [TMG][TFA] (Scheme 2; entry a) compared to those methods using other formylation strategies. ${ }^{9-14}$ Various aromatic, heteroaromatic, aliphatic (cyclic and acyclic) and heterocyclic amines were treated with formic acid (1: $1.2 \mathrm{~mol} / \mathrm{mol})$ at ambient temperature in $1 \mathrm{mmol}$ [TMG][TFA] ${ }^{28}$ and the results are summarized in Scheme 2. Nearly all the amines reacted efficiently affording the corresponding $\mathrm{N}$-formyl products in good to excellent yields in 2-30 min. Aliphatic (cyclic and acyclic) primary and secondary amines gave the corresponding $N$-formyl products in $94-100 \%$ yields. Anilines containing both electron-donating and electron-withdrawing groups underwent the conversin smoothly. Previously, the N-formylation of anilines having electron-withdrawing groups was found to be difficult $^{17}$ (entry $\mathrm{f}$ ). The chemoselectivity of the [TMG][TFA] was also assessed by performing formylation of amines in bifunctional compounds (Scheme 2; entries i-1). Excellent chemoselectivity was observed for substrates with $\mathrm{OH}$ functionalities providing $\mathrm{N}$-formyl derivatives as the only products, and no side reaction took place. The [TMG][TFA] catalyzed Nformylation strategy was also studied for the formylation of some selected chiral amino acid alcohols and esters. To further investigate the scope of the reaction, imidazole, $N, N$ dimethylhydrazine and $N$-hydroxyaniline were studied under similar conditions. All amine derivatives converted readily into the corresponding $\mathrm{N}$-formamide derivatives (Scheme 2, entries $\mathrm{r}-\mathrm{t}$ ). For the purpose of comparison, Performances of IL and various previously used catalysts are compared in Table 1. 


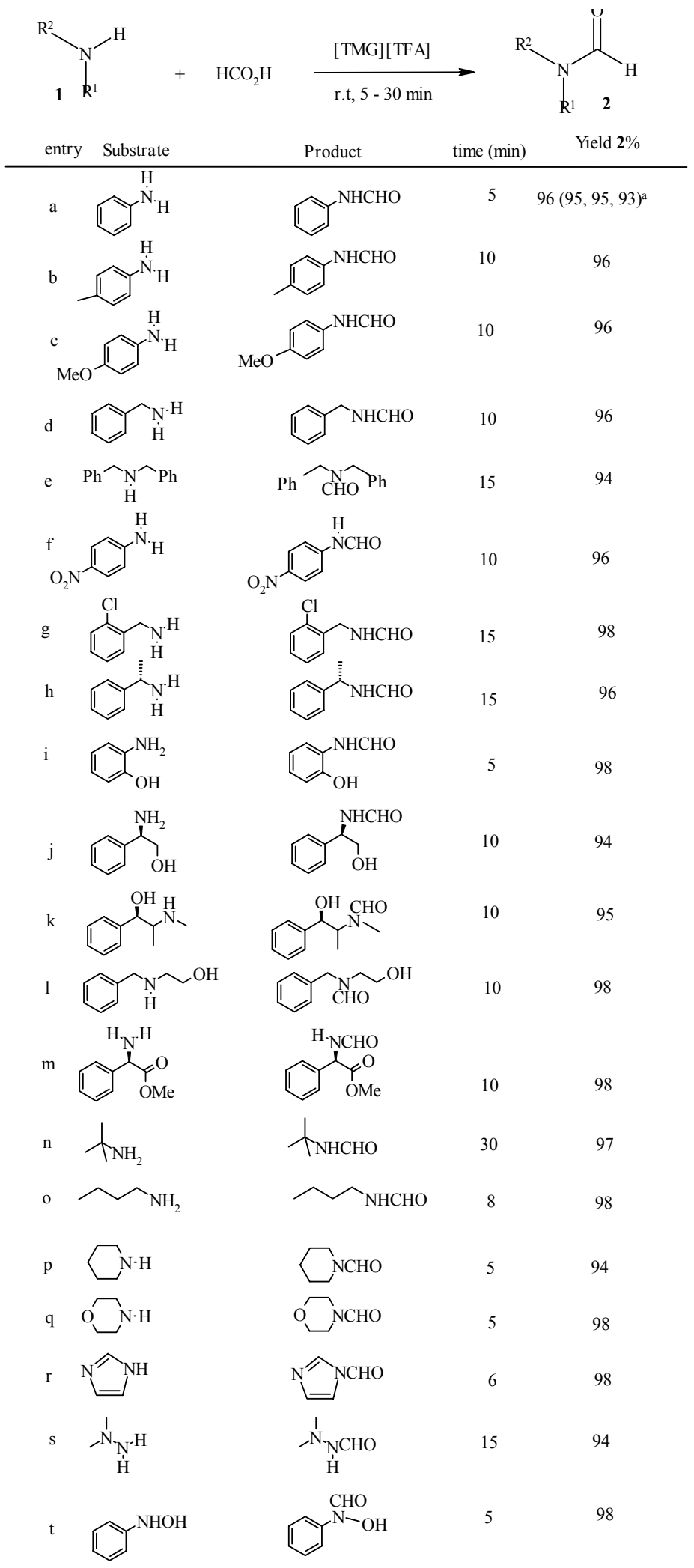

${ }^{a}$ The yields of four subsequent runs using the same recovered ionic liquid.

Scheme 2. [TMG] [TFA] promoted $N$-formylation of amines. 
Table 1. Compared performance of various methods in the $N$-formylation of aniline

\begin{tabular}{lccc}
\hline Entry & formylation method & Time & Yield (\%) \\
\hline 1 & Vilsmeier-Haack reaction & $2 \mathrm{~h}$ & $75^{28}$ \\
2 & DMF-POCl $_{3}$ & $5 \mathrm{~h}$ & $65^{8}$ \\
3 & Acetic-formic anhydride & $6 \mathrm{~h}$ & $85^{6}$ \\
4 & Ethylformate & $4 \mathrm{~h}$ & $80^{10}$ \\
5 & Ammonium formate & $0.5 \mathrm{~h}$ & $85^{14}$ \\
6 & $\mathrm{HCO}_{2} \mathrm{H}-\mathrm{PEG}$ & $1 \mathrm{~h}$ & $90^{14}$ \\
7 & $\mathrm{HCO}_{2} \mathrm{H}-\mathrm{ZnO}$ & $20 \mathrm{~min}$ & $92{ }^{13}$ \\
8 & $\mathrm{HCO}_{2} \mathrm{H}-\mathrm{IL}$ & $5 \mathrm{~min}$ & 98 \\
\hline
\end{tabular}

The feasibility of any process depends on the reusability. In the present work, the reusability of [TMG][TFA] was assessed by conducting $\mathrm{N}$-formylation of aniline over four successive cycles without any pre-treatment of the [TMG][TFA]. The results indicate no significant loss of activity of the acidic guanidine derived ionic liquid.

\section{Conclusions}

In summary, we have described here the first example of the $\mathrm{N}$-formylation of amines with formic acid in protic ionic liquid. The reported protocol is efficient, inexpensive, chemoselective and the ionic liquid is reusable. The advantages of the present method are (i) the use of a green and easy to handle ionic liquid; (ii) the ease of preparation of [TMG][TFA]; (iii) mild and catalyst-free reaction conditions; (iv) the ease of extraction of the product/ substrate from ionic liquid; (v) [TMG][TFA] could be directly reused after drying without any significant loss of activity and (vii) excellent chemoselectivity.

\section{Experimental Section}

General Procedure. To a mixture of $\mathrm{HCO}_{2} \mathrm{H}(1.2 \mathrm{mmol})$ and [TMG][TFA] (229 $\left.\mathrm{mg}, 1 \mathrm{mmol}\right)$ was added an amine $(1 \mathrm{mmol})$, and then the reaction mixture was stirred with a magnetic stirrer at room temperature. The progress of the reaction was monitored by TLC. After the reaction was complete, EtOAc was added to the reaction mixture, and [TMG][TFA] was removed by filtration. After removal of the solvent, the pure product was obtained. The physical data (mp, IR, NMR) of known compounds were found to be identical with those reported in the literature. ${ }^{11-14}$ Spectra data for selected products: 2b. ${ }^{1} \mathrm{H}$ NMR $\left(500 \mathrm{MHz}, \mathrm{CDCl}_{3}\right): 50: 50$ (cis/trans) $\delta=8.60(\mathrm{~d}, 0.5 \mathrm{H}, J=8.0 \mathrm{~Hz}$, trans), 8.52 (brs, $0.5 \mathrm{H}$, trans), $8.31(\mathrm{~d}, 0.5 \mathrm{H}, J=8.0 \mathrm{~Hz}$, cis), 7.92 (brs, $0.5 \mathrm{H}, c i s), 7.42$ (d, $1 \mathrm{H}, J=8.3 \mathrm{~Hz}$, cis), 7.13 (d, $1 \mathrm{H}, J=8.3 \mathrm{~Hz}$, trans), 7.10 (d, 1 
$\mathrm{H}, J=8.3 \mathrm{~Hz}$, cis $), 6.98(\mathrm{~d}, 1 \mathrm{H}, J=8.3 \mathrm{~Hz}$, trans $), 2.31$ (s, $1.5 \mathrm{H}$, trans $), 2.29(\mathrm{~s}, 1.5 \mathrm{H}$, cis $) ;{ }^{13} \mathrm{C}$ NMR $\left(125 \mathrm{MHz}, \mathrm{CDCl}_{3}\right): \delta=21.2\left(\mathrm{CH}_{3}\right), 21.3\left(\mathrm{CH}_{3}\right), 119.5(\mathrm{CH}), 120.6(\mathrm{CH}), 130.0(\mathrm{CH})$, $130.6(\mathrm{CH}), 134.7-134.9(\mathrm{CH}), 135.5(\mathrm{C}), 159.8(\mathrm{C}=\mathrm{O}$, cis $), 163.6(\mathrm{C}=\mathrm{O}$, trans $) ; 2 e:{ }^{1} \mathrm{H}$ NMR (500 MHz, $\left.\mathrm{CDCl}_{3}\right): 85: 15$ (cis/trans) $\delta=8.29(\mathrm{~s}, 0.85 \mathrm{H}$, cis $), 8.22(\mathrm{~d}, 0.15 \mathrm{H}, J=12.0 \mathrm{~Hz}$, trans), 7.29 (d, 0.15 H, J=12.0 Hz, trans), 7.24- 7.47 (m, $5 \mathrm{H}, \mathrm{Ar}-\mathrm{H}), 5.75$ (s, $0.85 \mathrm{H}$, cis), 4.51 (d, 1.7 $\mathrm{H}, J=6.0 \mathrm{~Hz}, c i s), 4.44(\mathrm{~d}, 0.3 \mathrm{H}, J=6.3 \mathrm{~Hz}$, trans $) ;{ }^{13} \mathrm{C} \mathrm{NMR}\left(125 \mathrm{MHz}, \mathrm{CDCl}_{3}\right): \delta=41.5$ $\left(\mathrm{CH}_{2}\right), 126.8(\mathrm{CH}), 129.1(\mathrm{CH}), 130.6(\mathrm{CH}), 134.1(\mathrm{C}), 162.3(\mathrm{C}=\mathrm{O})$.

\section{Acknowledgements}

This research was supported by the Islamic Azad University, Buinzahra Branch.

\section{References}

1. Green, T. W.; Wuts, P. G. M. Protective Groups in Organic Synthesis, 3rd Ed.; WileyInterscience: New York, 1999; Sheehan, J. C.; Yang, D. D. H. J. Am. Chem. Soc. 1958, 80 , 1154.

2. Waki, J.; Meienhofer, J. J. Org. Chem. 1977, 42, 2019. (b) Ugi, I. Angew. Chem. Int. Ed. Engl. 1982, 21, 810.

3. Schollkopf, U. Angew. Chem., Int. Ed. 1977, 16, 339.

4. Effenberger, F.; Eichhorn, J. Tetrahedron: Asymmetry 1997, 8, 469; Humber, L. G. J. Med. Chem. 1971, 14, 982.

5. Han, Y.; Cai, L. Tetrahedron Lett. 1997, 38, 5423.

6. Strazzolini, P.; Giumanini, A. G.; Cauci, S. Tetrahedron 1990, 46, 1081.

7. Blicke, F. F.; Lu, C. J. J. Am. Chem. Soc. 1952, 74, 3933.

8. Waki, J.; Meienhofer, J. J. Org. Chem. 1977, 42, 2019.

9. Chen, F. M. F.; Benoiton, N. L. Synthesis 1979, 709.

10. Yale, H. L. J. Org. Chem. 1971, 36, 3238.. Kisfaludy, L.; Laszlo, O. Synthesis 1987, 510; Neveux, M.; Bruneau, C.; Dixneuf, P. H. J. Chem. Soc., Perkin Trans. I. 1991, 1197;

Duczek, W.; Deutsch, J.; Vieth, S.; Niclas, H.-J. Synthesis 1996, 37.

11. Reddy, P. G.; Kumar, G. D. K.; Baskaran, S. Tetrahedron Lett. 2000, 41, 9149.

12. Hill, D. R.; Hasiao, C.-N.; Kurukulasuriya, R.; Wittenberger, S. J. Org. Lett. 2002, 4, 111.

13. Hosseni-Sarvari, M.; Sharghi, H. J. Org. Chem. 2006, 71, 6652.

14. Jung, S. H.; Ahn, J. H.; Park, S. K.; Choi, J.-K. Bull. Korean Chem. Soc. 2002, 23, 149; Biswanath, D.; Meddeboina, K.; Balasubramanayam. P.; Boyapati. V. D.; Nandan. K. D. Tetrahedron Lett. 2008, 49, 2225.

15. Wasserscheid. P.; Welton. T. In Ionic Liquids in Synthesis, Vols. 1 and 2, 2nd Ed., WileyVCH: Weinheim, 2008. 
16. Wang, W. J.; Shao, I. L.; Chen, W. P.; Yang, J. C. Catal. Commun. 2008, 9, 337.

17. Zaleska, B.; Karelu, M.; Flasiński, M.; Serda. P. Arkivoc 2007, (vi) 64.

18. Maradolla, M. B.; Allam, S. K.; Mandha, A.; Chandramouli, G. V. P. Arkivoc 2008, (xv), 42.

19. Ganeshpure, P. A.; George, G.; Das . J. Arkivoc 2007 (viii) 273-278

20. Vallette, H.; Ferron, L.; Coquerel, G.; Guillen, F.; Plaquevent, J. C. Akivoc 2006, (iv) 200.

21. Wilkes, J. S.; J. Mol. Catal. A: Chem. 2004, 214, 11.

22. Gao, H.; Han, B.; Li, J.; Jiang, T.; Liu, Z.; Wu, W.; Chang, Y.; Zhang, J. Synth. Commun. 2004, 34, 3083.

23. Huang. J.; Jiang. T.; Gao. H.; Han. B.; Liu. Z..; Wu. W.; Chang. Y.; Zhao. G. Angew. Chem., Int. Ed. 2004, 43, 1397.

24. Jiang, T.; Gao, H.; Han, B.; Zhao, G.; Chang, Y.; Wu, W.; Gao, Yang, L. G. Tetrahedron Lett. 2004, 45, 2699.

25. Shaabani, A.; Samadi, S.; Badri, Z.; Rahmati, A. Catal. Lett. 2005, 104, 39.

26. Shaabani, A.; Rahmati, A. Catal. Lett. 2005, 100, 177.

27. Zhu, A. L.; Jiang, T.; Han, B. X.; Huang, J.; Zhang, J. C.; Ma, X. M. New J. Chem. 2006, 30, 736.

28. Downie, I. M.; Earle, M. J.; Heaney, H.; Shubaibar, K. F. Tetrahedron 1993, 49, 4015. 